\title{
Bisico Bulk Fill - der Alleskönner mit perfekten Fließeigenschaften
}

\begin{abstract}
Bisico Bulk Fill ist unser neues fließfähiges Komposit für zuverlässige direkte Restaurationen im Seitenzahnbereich. Die gesamte Kavität kann in der Bulk-Fill-Technik in einer bis zu vier Millimeter dicken Schicht aufgefüllt werden.
\end{abstract}

Das ist sowohl eine Arbeitserleichterung als auch eine Arbeitsbeschleunigung. Dank seiner Konsistenz ist es modellierbar und fließt sehr gut an die Kavitätenwände an.

Die dünnen Applikationskanülen der Bulk-Fill-Fillies erlauben eine sichere Applikation und eine blasenfreie Adaption des Komposits an Kavitätenwände und -boden. Der hohe Füllstoffanteil garantiert bei hoher Elastizität einen geringen Schrumpf, was sich positiv auf eine geringe Größe des Randspaltes auswirkt.

Durch den Chamäleon-Effekt von Bisico Bulk Fill in der Farbe universal Dentin passt sich die Füllung ausgezeichnet an die natürliche Zahnfarbe an. Die Füllung wird praktisch unsichtbar. Restaurationen mit Bisico Bulk Fill lassen sich sehr gut ausarbeiten und polieren.

\section{Alle Vorteile im Überblick}

- Stabil: ausgezeichnete physikalische Eigenschaften, geringer Schrumpf, hohe Elastizität

- Zeitsparend: einfache, schnelle Verarbeitung in der Bulk-FillTechnik, 4 mm Schichtstärke

- Ästhetisch: universal Dentinfarbe mit natürlicher Farbanpassung

- Fließfähig: ausgezeichnete Adaption an Kavitätenboden und Kavitätenwände

- Hochviskos: modellierbar, keine weitere Schicht erforderlich

- Röntgenopak: zuverlässige Diagnosen dank hoher Röntgenopazität

- Bis-GMA frei: optimierte Biokompatibilität

Lieferform: 20 Fillies a 0,25 g
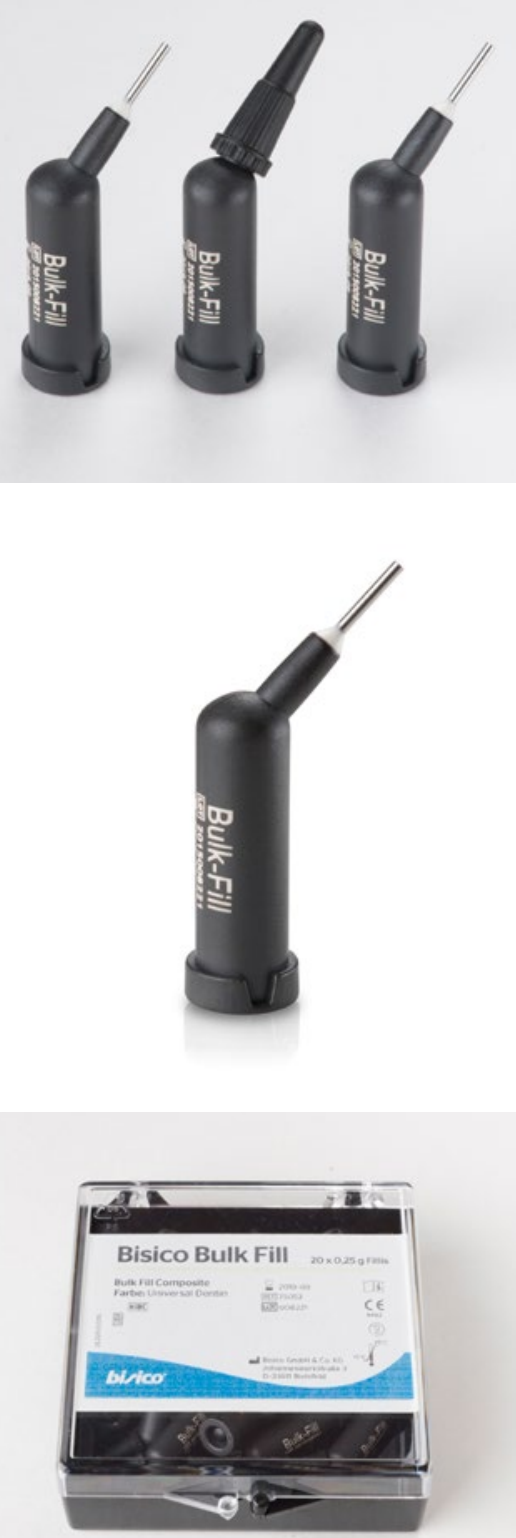